\title{
Nutrient and toxin interactions in neurodegenerative disease
}

\author{
BY PETER H. EVANS \\ MRC Dunn Nutrition Unit, Milton Road, Cambridge CB4 $1 X J$
}

The brain is the most complex organ of the body. Its effective function is dependent on its unique anatomical structure and neuronal cell morphology, together with the efficient coordination of its metabolic and physiological processes. The degenerative diseases of the brain, for example Huntington's, Parkinson's and Alzheimer's disease (AD), are generally characterized by an associated loss of functional neurones, with accompanying motor, memory and cognitive deficits.

In the case of familial amyotrophic lateral sclerosis (ALS; Deng et al. 1993), Huntington's disease, early-onset dementia of familial AD (Martin, 1993), and the prion diseases (the spongiform encephalopathies, i.e. Creutzfeldt-Jacob disease and the Gerstmann-Sträussler-Scheinker syndrome; Prusiner, 1991), a genetic aetiology has been demonstrated. The larger number of so-called sporadic cases of AD which occur in the 8th and 9th decades of life, suggests that environmental factors are also operative. Even so, recent findings concerning apolipoprotein $\mathrm{E} \epsilon 4$ allele indicate genetic polymorphisms are significant risk factors in the development of late-onset $\mathrm{AD}$ as well (Saunders et al. 1993). Hence, senile dementia of the Alzheimer type, the most common of the neurodegenerative diseases, appears to be of multifactorial origin, presenting a complex interplay of genetic, environmental, and age-related factors (Calne et al. 1986).

\section{BRAIN RESEARCH}

Undertaking studies into the toxicological and nutritional aspects of neurodegeneration, poses a range of ethical, organizational, technical and financial, challenges. Since there is no laboratory test for $\mathrm{AD}$ and the definitive diagnosis is dependent on postmortem identification and quantification of the pathognomic intracellular neurofibrillary tangles and extracellular senile plaques within the brain, epidemiological and clinical investigations into $\mathrm{AD}$ are extremely problematic. However, tests for cognitive function, and development of new in vivo imaging techniques, namely magnetic resonance imaging and positron emission topography scans, do permit a degree of clinical assessment.

The inherent difficulty of research into the brain is compounded not only by the diverse range of neuronal and glial cell types and the complexity of the integrated neural network, but also by the properties of redundancy and plasticity exhibited by the brain. Brain damage related to degenerative change may not become apparent until the loss of neurones reaches a particular threshold level. Hence, cognitive deficits appearing in later life may not be directly caused by senility or the ageing process itself, but may be the result of developmental deficits or toxic damage which has occurred several decades earlier. Studies indicating the major significance of pre- or early postnatal nutrition to infant brain development (Lucas, 1993) and the subsequent development of disease in adult life (Barker et al. 1989), are of particular importance in relation to the nonreplicative nature of neuronal cells. While the significance of proper nutrition in early brain development is well appreciated, evidence of nutritional influences on intelligence 


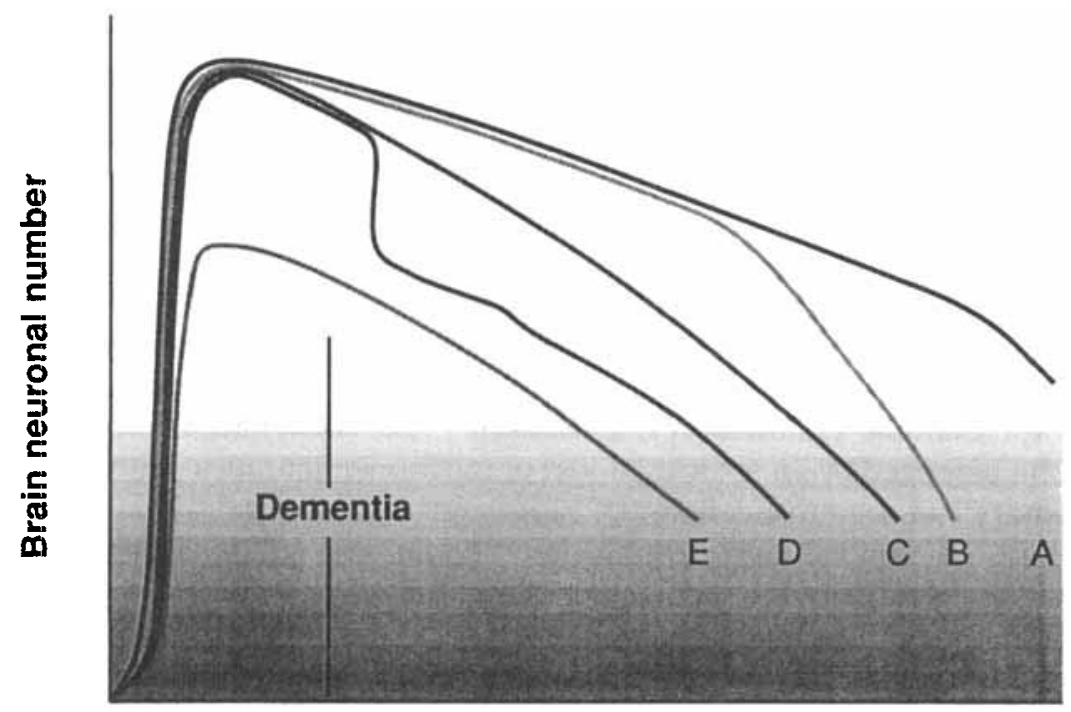

Age

Fig. 1. Loss of neurones with age. (A), Normal ageing; (B), senile Alzheimer's disease; (C), familial Alzheimer's disease: (D), early-life neurotoxic insult; (E), developmental neuronal deficit.

which has been presented with respect to micronutrient supplementation in schoolchildren, continues to arouse controversy (Benton, 1992). As illustrated in the generalized scheme (Fig. 1), the loss of neurones in later life, may be the consequence of neuronal degeneration occurring at various life stages, caused by a variety of adverse developmental, toxic, genetic and senile processes.

The plasticity of the brain means that such neuronal loss may be offset by various semi-adaptive modifications which allow a degree of compensatory retention of brain function. Such processes as proliferation of dendritic outgrowths, enchanced neurotransmitter synthesis, increased number of synaptosomes, and increased receptor density, may all contribute to an amelioration of adverse effects following a decline in neuronal number. Factors which inhibit neuronal loss may be expected to delay the onset of early dementia and reduce its rate of progression, thus contributing to a prolongation of active cognitive function. It may be envisaged that nutrients are of benefit both from their intrinsic biological effect on brain metabolism, and also by counteracting the injurious effects of environmental neurotoxins.

\section{ENVIRONMENTAL NEUROTOXINS}

The potential aetiological role of neurological toxins in degenerative brain diseases, has received considerable scientific and media prominence. Of the suggested causative agents, heavy-metal pollutants have attracted particular attention. In particular, $\mathrm{Al}$, a known neurotoxic agent (Wisnieweski et al. 1982), has aroused controversy with regard to its putative aetiopathogenic role in AD (Rifat, 1994). Several epidemiological studies have revealed an association of AD with drinking-water Al content (Martyn, 1992). Analysis of brain tissue utilizing a variety of sensitive multi-elemental and microprobe 
techniques including: neutron activation (Ward \& Mason, 1987), electron microscope X-ray energy dispersion (Singhrao et al. 1990), and laser (Lovell et al. 1993) and proton (Landsberg et al. 1992) microprobe, have produced inconsistent findings. Although bulk brain concentrations of $\mathrm{Al}$ appear not to be generally raised, solid-state NMR analysis has revealed increased accretion of co-localized $\mathrm{Al}$ and $\mathrm{Si}$ to form plaque core deposits of aluminosilicate (Candy et al. 1986). Elevated levels of Si in cerebrospinal fluid have been found to occur in senile forms of AD (Hershey et al. 1984).

$\mathrm{Al}$ accumulates slowly within the body, small amounts being absorbed from the diet in the small intestine and rapidly excreted (Powell \& Thompson, 1993). Ingress may also occur via inhalation of aluminosilicate clay dust, or even as $\mathrm{Al}_{\mathbf{1}} \mathrm{l}-\mathrm{Al}_{2} \mathrm{O}_{3}$ (McIntyre powder), once used in the prophylactic treatment of silicosis (Rif: $:$ et al. 1990). Access across the blood-brain barrier is mediated by binding to tran iferrin (Roskams \& Connor, 1990). More speculatively, pathological studies indicating early involvement of the olfactory tract in AD (Mann et al. 1988), together with experimental investigations into the olfactory uptake of $\mathrm{Al}$ (Perl \& Good, 1987), suggests that the nose may provide an alternative direct route of entry of toxins into the brain.

Neutron activation has also revealed increased concentrations of $\mathrm{Hg}$ in $\mathrm{AD}$ brain regions (Thompson et al. 1988), a finding pertinent to the controversy concerning the stability of dental amalgam. Likewise, Sn has also been implicated in dementia (Corrigan et al. 1991). Early exposure to $\mathrm{Pb}$ has been associated with dysfunction of the hippocampus, an area of the brain important in memory function (Petit et al. 1983), and also with the subsequent adult appearance of neurofibrillary tangles (Nicklowitz \& Mandybur, 1975). Exposure of Australian aborigines to Mn-rich soils is associated with the Angurugu Syndrome, a Parkinson's-like disease similar to that found in Chilean Mn miners (Florence \& Stauber, 1989). In addition, increased $\mathrm{Al}$ and Fe occurs in the substantia nigra of Parkinson's disease brains (Hirsch et al. 1991).

\section{TOXICO-DIETETICS}

Research concerning the modulation of toxicity by diet has grown considerably with the appreciation of the specific nutritional factors and mechanisms involved (Netter, 1986). Interactions of toxic and nutrient elements are many, varied and complex. Absorption of $\mathrm{Pb}$ is enhanced by dietary deficiencies of $\mathrm{Ca}, \mathrm{Fe}, \mathrm{Zn}$ and $\mathrm{Cu}$, and dietary Se is protective against the toxic effect of $\mathrm{Hg}$ and $\mathrm{Cd}$ (Couzy et al. 1993). Experimental dietary deficiency of $\mathrm{Ca}$ and $\mathrm{Mg}$ enhances $\mathrm{Al}$ uptake in monkeys, a finding of relevance to the pathogenesis of ALS, a parkinsonian-dementia prevalent in the Pacific islands of Guam (Yasui et al. 1991). Animal studies have revealed enhanced memory in aged rats fed on a diet high in $\mathrm{Mg}$, mediated possibly by cellular Ca interactions (Landfield \& Morgan, 1984), and suboptimal dietary $\mathrm{Zn}$ increases $\mathrm{Al}$ accumulation in the brains of rats (Wenk \& Stemmer, 1983). Zn has an important role in neuronal function, being found in high concentrations in the hippocampus (Dreosti, 1989). Zn concentrations in blood plasma decrease with age (Lindeman et al. 1971) and are further decreased in AD brains (Ward \& Mason, 1987). Confirmation of the hypothesis that gastrointestinal absorption of $\mathrm{Al}$ is inhibited by dietary Si levels (Birchall, 1993), has been provided both in humans (Edwardson et al. 1993) and in brains of aged rats (Carlisle \& Curran, 1987). Interestingly, $\mathrm{Al}$ deposition was actually increased in rat spleen, possibly due to uptake of colloidal microprecipitates of aluminosilicates (Quartley et al. 1993). However, the 
question of whether the association of $\mathrm{Al}$ and $\mathrm{Si}$ in serum exerts a protective effect, is unanswered (Fahal et al. 1994). The role of citrate and ascorbate in promoting absorption and excretion of $\mathrm{Al}$, awaits clarification (Domingo et al. 1991). Absorption of aluminium citrate in humans increases with age, and in younger AD subjects compared with age-matched controls (Taylor et al. 1992).

\section{BRAIN OXIDATIVE STRESS}

The prevalence of dementia of the $\mathrm{AD}$ type is strongly correlated with old age, while dementia in familial AD and Down's syndrome, generally appears several decades earlier. A proposed mechanism of the ageing process involves the injurious activity of free radicals and associated reactive $\mathrm{O}$ metabolites (ROM), namely superoxide and hydroxyl radicals, and $\mathrm{H}_{2} \mathrm{O}_{2}$ (Harman, 1984). As a result of reactivity with DNA, proteins and lipids, and the consequent tissue injury to vital cellular functions, ROM have been implicated in various pathological and age-related disease processes. An age-dependent increase in superoxide generation (Sawada et al. 1992), lipid peroxides (Mizuno \& Ohta, 1986), and cerebral glutathione susceptibility to oxidant-induced stress (Benzi et al. 1989), has been demonstrated in rats.

The brain is particularly susceptible to oxidant-mediated damage, exhibiting high metabolic activity, and contains high levels of readily-oxidizable polyunsaturated fatty acids. Antioxidant protection in the brain is largely provided by vitamin E, glutathione, ascorbate and carnosine (Kohen et al. 1988; Sokol, 1989; Grünewald, 1993). In addition, participation of 'catalytic' $\mathrm{Fe}$ in free-radical reactions within the brain (Gutteridge, 1992), has stimulated interest in its neuropathogenic role (Sachdev, 1993). Fe-mediated peroxidation of brain membrane lipids may be augmented in the presence of $\mathrm{Al}$ ions (Oteiza et al. 1993). ROM have been implicated in a variety of neuropathological disorders, including Parkinson's disease, AD, trauma, and ischaemia (Halliwell, 1992; Evans, 1993).

Pathogenic reactions of ROM in brain tissues include peroxidation of synaptosomes (Binkova et al. 1990), and inhibition of mitochondria (Hillered \& Ernster, 1983). ROM also compromise blood-brain barrier functions (Greenwood, 1991), and act as mediators of neurotoxicity (LeBel \& Bondy, 1991). However, in addition to their role in inducing pathological changes, age-related studies of superoxide dismutase ( $E C$ 1.15.1.1; SOD) show ROM involvement in foetal brain development, indicating a physiological function (Takashima et al. 1990).

\section{ALZHEIMER'S DISEASE AND FREE RADICALS}

A clue to the pathogenesis of dementia was the finding that Down's syndrome subjects, who exhibit chromosome-21 trisomy, possess an extra copy of the $\mathrm{Cu}-\mathrm{Zn}$ SOD gene, suggesting perturbation of the redox balance (Kedziora \& Bartosz, 1988). Evidence of redox changes in $\mathrm{AD}$ brains is indicated by the increased $\mathrm{O}$-stimulated peroxidation (Götz et al. 1992), accumulation of lipofuscin (Dowson, 1989), and oxidatively-modified dysfunctional glutamine synthetase (EC 6.3.1.2; Smith et al. 1991). Such changes are possibly related to a disruption of $\mathrm{Fe}$ homeostasis (Connor et al. 1992), and to monoamine oxidase B-related generation of $\mathrm{H}_{2} \mathrm{O}_{2}$ (Zetzsche \& Chan-Palay, 1992). Brain antioxidant homocarnosine is decreased, although cortical levels of glutathione 
and bulk brain concentrations of vitamin E are reportedly normal in AD (Perry et al. 1987; Metcalfe et al. 1989). However, the absence of altered brain vitamin $E$ levels in experimental ischaemia-reperfusion oxidative injury in rats, indicates that vitamin $\mathrm{E}$ may not be a sensitive index of ROM-mediated brain damage (Yue et al. 1993). In peripheral tissues, blood plasma concentrations of vitamins $\mathrm{A}$ and $\mathrm{E}$, and carotenoids, are decreased (Zaman et al. 1992).

\section{AMYLOID, MICROGLIA AND FREE RADICALS}

Pathological studies of $A D$ indicate that deposition of the $\beta / A 4$ protein and accompanying formation of insoluble amyloid fibrils, is associated with the consequent accumulation of brain macrophages-microglia at the plaque site (Mann et al. 1992). Indeed, $\beta / A 4$ protein is chemotactic for microglia in vitro (Davis et al. 1992). Activation of microglia and related release of inflammatory mediators has been implicated in the pathogenesis of degenerative neurological diseases (McGeer et al. 1993). Of especial significance is the finding that activated microglia are potent producers of ROM in response to a number of immunological and chemical stimuli (Sonderer et al. 1987). The question as to whether the accumulation of $\mathrm{Al}$ and $\mathrm{Si}$ within the plaque cores represents merely an inconsequential epiphenomenon, or is indeed of aetiopathogenic importance, is a key one to understanding the potential toxic role of $\mathrm{Al}$ in $\mathrm{AD}$. Pertinent to this issue, in vitro chemiluminescent studies have shown microglia to generate ROM when exposed to various model synthetic and mineral aluminosilicate particulates of differing composition, size, and fibrillar morphology (Evans et al. 1992a). This finding, akin to pneumoconiosis, is consistent with the so-called cephaloconiosis hypothesis of AD (Evans et al. 1991), namely that analogous in vivo aluminosilicate-amyloid fibril plaque deposits act as a persistent reactive nidus, and induce the chronic generation of injurious ROM by endogenous brain microglial cells. Inhibition of macrophage-derived ROM production by vitamin E (Sakamoto et al. 1990), confirms the therapeutic potential of antioxidant micronutrients to modify and prevent the proposed cephaloconiotic oxidative injury (Evans et al. 1992b).

In vitro aggregation of $\beta / \mathrm{A} 4$ protein to form insoluble amyloid fibrils is enhanced by oxidative reactions (Dyrks et al. 1992). It is interesting to speculate whether the enhanced binding of $\beta / A 4$ protein to oxidant-modified apolipoprotein allele E $\varepsilon 4$ (Strittmatter et al. 1993), may be exacerbated by environmental factors, namely $\mathrm{Al}$ and aluminosilicates, by the production of microglial ROM. Oxidized lipoproteins, together with impaired endothelial cell vasodilator function (Keaney et al. 1993), may thus contribute to the pathogenesis of $A D$ as well as to cerebrovascular dementia. Of allied interest, in vitro neurotoxicity of synthetic $\beta$ amyloid (Behl et al. 1992), and systemic casein-induced amyloidosis in mice (Harman et al. 1976), are inhibited by vitamin E. Cytotoxicity of microglial cells to neurones in culture is inhibited by catalase ( $E C$ 1.11.1.6), indicating the adverse effects of $\mathrm{H}_{2} \mathrm{O}_{2}$ (Théry et al. 1991). Immunostimulation of microglia with the resultant activation of nitric oxide synthase and consequent production of reactive $\mathrm{NO}$, has also been shown to be cytotoxic to co-cultured neuronal cells (Boje \& Arora, 1992). The ambivalent neurotoxic and neuroprotective effects of nitric monoxide have been related to the activity of the alternative redox states of nitric oxide (NO•) and the nitrosonium ion $\left(\mathrm{NO}^{+}\right)$respectively (Lipton et al. 1993). 


\section{NEUROTOXIC XENOBIOTICS}

The brain, despite the general effectiveness of the blood-brain barrier, which may be compromised in disease and in the aged, is exposed to a wide variety of environmental foreign agents. Metabolism of xenobiotic organic chemicals by brain NADPHcytochrome P450 generates superoxide radicals and, hence, contributes to oxidative stress (Ghersi-Egea et al. 1991). Dietary excitotoxins, i.e. the amino acids glutamate and aspartate, are also associated with oxidative stress, and have been implicated in the pathophysiology of AD (Maragos et al. 1987), stroke, trauma and seizures (Coyle \& Puttfarken, 1993). Nutritional toxicology, and the study of food-borne neurotoxins, for example cycasin, a component of the cycad palm and a possible cause of endemic ALS found in Guam, has provided significant clues to understanding specific neuropathogenic mechanisms (Meldrum, 1993). Similarly, the identification of 1-methyl-4-phenyl-1,2,3,6tetrahydropyridine as the contaminant in synthetic heroin responsible for the parkinsonian syndrome which occurred in Californian drug addicts, illustrates the important potential causal role of environmental redox chemicals in idiopathic Parkinson's disease (Adams \& Odunze, 1991).

\section{DIET IN THE ELDERLY}

The challenge to determine and meet the nutritional requirements of the elderly in order to optimize health and minimize disease, is a substantial one. Dietary studies of the elderly undertaken in the UK (Campbell et al. 1989), and Europe (SENECA, 1991), have revealled wide variations in micronutrient intake, with significant proportions of the elderly possibly marginally deficient in antioxidant vitamins and minerals.

Nutrition is important for cognitive function in the elderly (Rosenberg \& Miller, 1992), and epidemiological investigations have linked malnutrition with an increased risk of late-onset AD (Henderson et al. 1992). In addition to dietary deficiencies, maladsorption of vitamin $B_{12}$ has been demonstrated in psychogeriatric patients (Burns et al. 1986). The degree of cognitive impairment in $\mathrm{AD}$ correlates with the decrease in serum vitamin $\mathrm{B}_{12}$, and would appear to be disease-related and not only diet-related (Levitt \& Karlinsky, 1992). The finding that nitrous oxide and associated hydroxyl radical inactivates cobalamin (Haurani, 1989), suggests that the depletion of vitamin $B_{12}$ in AD may be caused by microglial ROM. Allied studies of vitamin status in the elderly also have shown a correlation of cognitive dysfunction with decreased erythrocyte folic acid (Sommer \& Wolkowitz, 1988). At the other end of the age spectrum, maternal deficiency of vitamin $B_{6}$ impairs foetal brain development (Guilarte, 1993), abnormalities that may predispose to adult neurodegeneration.

\section{PHARMACOLOGY OF NEURODEGENERATION}

The partial success of various pharmacological agents, namely metal chelators, and anti-inflammatory and antioxidant drugs used in treating dementia, illustrate the significance of the aetiopathogenic mechanisms involved. The reported beneficial effects of treating $\mathrm{AD}$ with the chelator desferrioxamine, instigated for the removal of the putative aetiological toxin $\mathrm{Al}$, may have been due also, to chelation of redox-active $\mathrm{Fe}$ (McLachlan et al. 1991). The 21-aminosteroidal lazeroid, which inhibits experimental brain ischaemia injury by its antioxidant sparing action on brain vitamins $\mathrm{C}$ and $\mathrm{E}$ (Sato 
\& Hall, 1992), may be expected to be of therapeutic worth in AD. The finding that the anti-inflammatory drug indomethacin is of value, supports the view that inflammatory microglial cells are of pathogenic pertinence in AD (Rogers et al. 1993). Treatment of Parkinson's disease with the monamine oxidase inhibitor drug deprenyl has been shown to slow the deterioration; however, co-administration of vitamin E appeared not to produce additional benefits (Parkinson Study Group, 1993).

\section{MICRONUTRIENTS, COGNITION AND NEURODEGENERATION}

The clinical use of antioxidant micronutrients, i.e. vitamins $\mathrm{C}$ and $\mathrm{E}, \beta$-carotene, Se and $\mathrm{Zn}$, in the treatment of a variety of diseases involving immune deficiencies, inflammation, ischaemia and vascular thrombosis, has long been advocated (Crary et al. 1984). Trials using various combinations of antioxidants, have been shown to be of some clinical value in the treatment of geriatric patients (Clausen et al. 1989) and in subjects with early Parkinson's disease (Fahn, 1992). Therapeutic investigations in AD subjects with vitamins $B_{1}, B_{2}, B_{6}$ and $C$ cocktails including thiamin, riboflavin, pyridoxine and ascorbic acid (Burns et al. 1989), and others containing $\mathrm{Zn}$, Se and fatty acids (Van Rhijn et al. 1990; Constantinidis, 1992), have reported varying degrees of improvement in psychological and cognitive function. The need for additional carefully controlled clinical trials in this field of nutritional medicine and prevention, is of special importance.

\section{CONCLUSION}

Predicted demographic change in the next few decades indicate a large increase in the number and proportion of the elderly, and particularly of the very old. With the anticipated rapid rise in the prevalence of dementia and other age-related neurodegenerative diseases, severe medical and social problems will be encountered. Recognition of the importance of research into function and diseases of the brain, has resulted in pronouncements in the USA and the EEU of the planned 'Decade of the Brain', and initiation by the USA National Academy of Sciences' Institute of Medicine of the 'Human Brain Project'. The National Institute of Health of the USA has identified the prevention of neurodegenerative diseases as a medical research priority. In the UK, similar moves to address these pressing matters are beginning to enter the medical, governmental and public consciousness. The important role which nutritional factors play in modulating cognitive function and neurodegeneration provides a significant challenge and opportunity for worthwhile research endeavour in the future.

I am indebted to my colleagues Professor Eiji Yano, Dr Jacek Klinowski, Professor Ernst Peterhans, Dr Thomas Bürge, and Dr Chris Bates, for their valued contributions.

\section{REFERENCES}

Adams, J. D. \& Odunze, I. N. (1991). Oxygen free radicals and Parkinson's disease. Free Radical Biology \& Medicine 10, 161-169.

Barker, D. J. P., Osmand, C., Winter, P. D., Margetts, B. \& Simmonds, S. J. (1989). Weight in infancy and death from ischaemic heart disease. Lancet ii, 577-580.

Behl, C., Davis, J., Cole, G. M. \& Schubert, D. (1992). Vitamin E protects nerve cells from amyloid $\beta$ protein toxicity. Biochemical and Biophysical Research Communications 186, 944-950. 
Benton, D. (1992). Vitamin-mineral supplements and intelligence. Proceedings of the Nutrition Society 51, 295-302.

Benzi, G., Pastoris, O., Marsatico, F. \& Villa, R. F. (1989). Age-related effect induced by oxidative stress on the cerebral glutathione system. Neurochemical Research 14, 473-481.

Binkova, B., Erin, A. N., Sram, R. J. \& Topinka, J. (1990). Lipid peroxidation-induced changes in physical properties of annular lipids in rat brain synaptosomal membranes. General Physiology and Biophysics $\mathbf{9}$, 311-318.

Birchall, J. D. (1993). Dissolved silica and bioavailability of aluminium. Lancet 342, 299.

Boje, K. M. \& Arora, P. K. (1992). Microglial-produced nitric oxide and reactive nitrogen oxides mediate neuronal cell death. Brain Research 587, 250-256.

Burns, A., Gillett, D. S., Jacoby, R. \& Mibashan, R. S. (1986). Vitamin B ${ }_{12}$ absorption in psychogeriatric patients. International Journal of Geriatric Psychiatry 1, 141-143.

Burns, A., Marsh, A. \& Bender, D. A. (1989). A trial of vitamin supplementation in senile dementia. International Journal of Geriatric Psychiatry 4, 333-338.

Calne, D. B., McGeer, E., Eisen, A. \& Spencer, P. (1986). Alzheimer's disease, Parkinson's disease and motorneurone disease: abiotropic interaction between ageing and environment Lancet ii, 1067-1070.

Campbell, D., Bunker, V. W., Thomas, A. J. \& Clayton, B. E. (1989). Selenium and vitamin E status of healthy and institutionalized elderly subjects: analysis of plasma, erythrocytes and platelets. British Journal of Nutrition 62, 221-227.

Candy, J. M., Klinowski, J., Perry, R. H., Perry, E. K., Fairbairn, A., Oakley, A. E., Carpenter, T. A., Atack, J. R., Blessed, G. \& Edwardson, J. A. (1986). Aluminosilicates and senile plaque formation in Alzheimer's disease. Lancet i, 354-357.

Carlisle, E. M. \& Curran, M. J. (1987). Effect of dietary silicon and aluminium on silicon and aluminium levels in rat brain. Alzheimer Disease and Associated Disorders 1, 83-89.

Clausen, J., Nielson, S. A. \& Kristensen, M. (1989). Biochemical and clinical effects of an antioxidative supplementation of geriatric patients. A double blind study. Biological Trace Element Research 20, $135-151$.

Connor, J. R., Menzies, S. L., St Martin, S. M. \& Mufson, E. J. (1992). A histochemical study of iron, transferrin, and ferritin in Alzheimer's disease brains. Journal of Neuroscience Research 31, 75-83.

Constantinidis, J. (1992). Treatment of Alzheimer's disease by zinc compounds. Drug Development Research 27, 1-14.

Corrigan, F. M., Van Rhijn, A. G., Ijomah, G., McIntyre, F., Skinner, E. R., Horrobin, D. F. \& Ward, N. I. (1991). Tin and fatty acids in dementia. Prostaglandins, Leukotrienes and Essential Fatty Acids 43, 229-238.

Couzy, F., Keen, C., Gershwin, M. E. \& Mareschi, J. P. (1993). Nutritional implications of the interactions between minerals. Progress in Food and Nutrition Science 17, 65-87.

Coyle, J. T. \& Puttfarken, P. (1993). Oxidative stress, glutamate, and neurodegenerative disorders. Science 262, 689-695.

Crary, E. J., Smyrna, G. \& McCarty, M. F. (1984). Potential clinical applications for high-dose nutritional antioxidants. Medical Hypothesis 13, 77-98.

Davis, J. B.. McMurray, H. F. \& Schubert, D. (1992). The amyloid beta-protein of Alzheimer's disease is chemotactic for mononuclear phagocytes. Biochemical and Biophysical Research Communications 189, 1096-1100.

Deng, H.-X., Hentati, A., Tainer, J. A., Iqbal, Z., Cayabyab, A., Hung, W. Y., Getzoff, E. D., Hu, P., Herzfeldt, B., Roos, R. P., Warner, C., Deng, G., Soriano, E., Smyth, C., Parge, H. E., Ahmed, A., Roses, A. D., Hallewell, R. A., Pericak-Vance, M. A. \& Siddique, T. (1993). Amyotrophic lateral sclerosis and structural defects in $\mathrm{Cu}, \mathrm{Zn}$ superoxide dismutase. Science 261, 1047-1051.

Domingo, J. L., Gomez, M., Llobet, J. M. \& Corbella, J. (1991). Influence of some dietary constituents on aluminum absorption and retention in rats. Kidney International 39, 598-601.

Dowson, J. H. (1989). Neuronal lipopigment: a marker for cognitive impairment and long-term effects of psychotropic drugs. British Journal of Psychiatry 155, 1-11.

Dreosti, I. E. (1989). Neurobiology of zinc. In Zinc in Human Biology. pp. 235-247 [C. F. Mills, editor]. London: Springer Verlag.

Dyrks, T., Dyrks, E., Hartmann, T., Masters, C. \& Beyreuther, K. (1992). Amyloidogenicity of $\beta A 4$ and BA4-bearing amyloid protein precursor fragments by metal-catalysed oxidation. Journal of Biological Chemistry 267, 18210-18217.

Edwardson, J. A., Moore, P. B., Ferrier, I. N., Lilley, J. S., Newton, G. W. A., Barker, J., Templar, J. \& Day, J. P. (1993). Effect of silicon on gastrointestinal absorption of aluminium. Lancet 342, 211-212. 
Evans, P. H. (1993). Free radicals in brain metabolism and pathology. British Medical Bulletin 49, 577-587.

Evans, P. H., Klinowski, J. \& Yano, E. (1991). Cephaloconiosis: a free radical perspective on the proposed particulate-induced etiopathogenesis of Alzheimer's dementia and related disorders. Medical Hypothesis 34, 209-219.

Evans, P. H., Peterhans, E., Bürge, T. \& Klinowski, J. (1992a). Aluminosilicate-induced free radical generation by murine brain glial cells in vitro: potential significance in the etiopathogenesis of Alzheimer's dementia. Dementia 3, 1-6.

Evans, P. H., Yano, E., Klinowski, J. \& Peterhans, E. (1992b). Oxidative damage in Alzheimer's dementia, and the potential etiopathogenic role of aluminosilicates, microglia and micronutrient interactions. In Free Radicals and Aging, pp. 178-189 [I. Emerit and B. Chance, editors]. Basel: Birkhäuser.

Fahal, I. H., Yaqoob, M., Williams, P. S., Ahmad, R., Roberts, N. B. \& Bell, G. M. (1994). Does silicon protect against aluminium in dialysis patients? Lancet $343,122-123$.

Fahn, S. (1992). A pilot trial of high-dose alpha-tocopherol and ascorbate in early Parkinson's disease. Annals of Neurology 32, S128-S132.

Florence, T. M. \& Stauber, J. L. (1989). Manganese catalysis of dopamine oxidation. The Science of the Total Environment 78, 233-240.

Ghersi-Egea, J.-F., Livertoux, M.-H., Minn, A., Perrin, R. \& Siest, G. (1991). Enzyme mediated superoxide radical formation initiated by exogenous molecules in rat brain preparations. Toxicology and Applied Pharmacology 110, 107-117.

Götz, M. E., Freyberger, A., Hauer, E., Burger, R., Sofic, E., Gsell, W., Heckers, S., Jellinger, K., Hebenstreit, G., Frölich, L., Beckmann, H. \& Reiderer, P. (1992). Susceptibility of brains from patients with Alzheimer's disease to oxygen-stimulated lipid peroxidation and differential scanning calorimetry. Dementia 3, 213-222.

Greenwood, J. (1991). Mechanisms of blood-brain barrier breakdown. Neuroradiology 33, 95-100.

Grünewald, R. A. (1993). Ascorbic acid in the brain. Brain Research Reviews 18, 123-133.

Guilarte, T. R. (1993). Vitamin $B_{6}$ and cognitive development: recent research findings from human and animal studies. Nutrition Reviews 51, 193-198.

Gutteridge, J. M. C. (1992). Iron and oxygen radicais in the brain. Annals of Neurology 32, S16-S21.

Halliwell, B. (1992). Reactive oxygen species and the central nervous system. Journal of Neurochemistry 59, 1609-1623.

Harman, D. (1984). Free radical theory of aging: the 'free radical' diseases. Age 7, 111-131.

Harman, D., Eddy, D. E. \& Noffsinger, J. (1976). Free radical theory of aging: inhibition of amyloidosis in mice by antioxidants; possible mechanism. Journal of the American Geriatrics Society 24, 203-210.

Haurani, F. I. (1989). The effects of free radicals on cobalamin and iron. Free Radical Research Communications 7, 241-243.

Henderson, A. S., Jorm, A. F., Korten, A. E., Creasey, H., McCusker, E., Broe, G. A., Longley, W. \& Anthony, J. C. (1992). Environmental risk factors for Alzheimer's disease: their relationship to age of onset and to familial or sporadic types. Psychological Medicine 22, 429-436.

Hershey, L. A., Hershey, C. O. \& Varnes, A. W. (1984). CSF silicon in dementia: a prospective study. Neurology 34, 1197-1201.

Hillered, L. \& Ernster, L. (1983). Respiratory activity of isolated rat brain mitochondria following in vitro exposure to oxygen radicals. Journal of Cerebral Blood Flow and Metabolism 3, 207-214.

Hirsch, E. C., Brandel, J.-P., Galle, P., Javoy-Agid, F. \& Agid, Y. (1991). Iron and aluminium increase in the substantia nigra of patients with Parkinson's disease: an X-ray microanalysis. Journal of Neurochemistry 56, 446-451.

Keaney, J. F., Gaziano, J. M., Xu, A., Frei, B., Curran-Celentano, J., Shwaery, G. T., Loscalzo, J. \& Vita, J. A. (1993). Dietary antioxidants preserve endothelium-dependent vessel relaxation in cholesterol-fed rabbits. Proceedings of National Academy of Sciences, USA 90,11880-11884.

Kedziora, J. \& Bartosz, G. (1988). Down's syndrome: a pathology involving the lack of balance of reactive oxygen species. Free Radical Biology \& Medicine 4, 317-330.

Kohen, R., Yamamoto, Y., Cundy, K. C. \& Ames, B. N. (1988). Antioxidant activity of carnosine, homocarnosine, and anserine present in muscle and brain. Proceedings of National Academy of Sciences, USA 85, 3175-3179.

Landfield, P. W. \& Morgan, G. A. (1984). Chronically elevating plasma $\mathrm{Mg}^{2}+$ improves hippocampal frequency potentiation and reversal learning in aged and young rats. Brain Research 322, 167-171.

Landsberg, J. P., McDonald, B. \& Watt, F. (1992). Absence of aluminium in neuritic plaque cores in Alzheimer's disease. Nature 360, 65-68. 
LeBel, C. P. \& Bondy, S. C. (1991). Oxygen radicals: common mediators of neurotoxicity. Neurotoxicology and Teratology 13, 341-346.

Levitt, A. J. \& Karlinsky, H. (1992). Folate, vitamin $B_{12}$ and cognitive impairment in patients with Alzheimer's disease. Acta Psychiatrica Scandinavica 86, 301-305.

Lindeman, R. D., Clark, M. L. \& Colmore, J. P. (1971). Influence of age and sex on plasma and red-cell zinc concentrations. Journal of Gerontology 26, 358-363.

Lipton, S. A., Choi, Y.-B., Pan, Z.-H., Lei, S. Z., Chen, H.-S. V., Sucher, N. J., Loscalzo, J., Singel, D. J. \& Stamler, J. S. (1993). A redox-based mechanism for the neuroprotective and neurodestructive effects of nitric oxide and related nitroso-compounds. Nature 364, 626-632.

Lovell, M. A., Ehmann, W. D. \& Markesbery, W. R. (1993). Laser microprobe analysis of brain aluminum in Alzheimer's disease. Annals of Neurology 33, 36-42.

Lucas, A. (1993). Influence of neonatal nutrition on long-term outcome. In Nutrition and the Low Birthweight Infant, pp. 183-196 [B. L. Salle and P. R. Swyer, editors]. New York: Raven Press.

McGeer, P. L., Kawamata, T., Walker, D. G., Akiyama, H., Tooyama, I. \& McGeer, E. G. (1993). Microglia in degenerative neurological disease. Glia 7, 84-92.

McLachlan, D. R. C., Dalton, A. J., Kruck, T. P. A., Bell, M. Y., Smith, W. L., Kalow, W. \& Andrews, D. F. (1991). Intramuscular desferrioxamine in patients with Alzheimer's disease. Lancet 337, 1304-1308.

Mann, D. M. A., Tucker, C. M. \& Yates, P. O. (1988). Alzheimer's disease: an olfactory connection? Mechanisms of Ageing and Development 42, 1-15.

Mann, D. M. A., Younis, N., Jones, D. \& Stoddart, R. W. (1992). The time course of pathological events in Down's syndrome with special reference to the involvement of microglial cells and deposits of $\beta / A 4$. Neurodegeneration 1, 201-215.

Maragos, W. F., Greenamyre, J. T., Penney, J. B. \& Young, A. B. (1987). Glutamate dysfunction in Alzheimer's disease: an hypothesis. Trends in Neurosciences 10, 65-68.

Martin, J. B. (1993). Molecular genetics of neurological diseases. Science 262, 674-676.

Martyn, C. N. (1992). The epidemiology of Alzheimer's disease in relation to aluminium. In Aluminium in Biology and Medicine, pp. 69-86 [D. J. Chadwick and J. Whelan, editors]. Chichester: Wiley.

Meldrum, B. (1993). Amino acids as dietary excitotoxins: a contribution to understanding neurodegenerative disorders. Brain Research Reviews 18, 293-314.

Metcalfe. T., Bowen, D. M. \& Muller, D. P. R. (1989). Vitamin E concentrations in human brain of patients with Alzheimer's disease, fetuses with Down's syndrome, centenarians and controls. Neurochemical Research 14, 1209-1212.

Mizuno, Y. \& Ohta, K. (1986). Regional distribution of thiobarbituric acid-reactive products, activities of enzymes regulating the metabolism of oxygen free radicals, and some of the related enzymes in adult and aged rat brains. Journal of Neurochemistry 46, 1344-1352.

Netter, K. J. (1986). Toxicodietetics: dietary alteration of toxic action. In New Concepts and Developments in Toxicology, pp. 139-144 [P. L. Chambers, P. Gehring and F. Sakai, editors]. Amsterdam: Elsevier.

Nicklowitz, W. J. \& Mandybur, T. I. (1975). Neurofibrillary changes following childhood lead encephalopathy. Journal of Neuropathology and Experimental Neurology 34, 445-455.

Oteiza, P. I., Fraga, C. G. \& Keen, C. L. (1993). Aluminum has both oxidant and antioxidant effects in mouse brain membranes. Archives of Biochemistry and Biophysics 300, 517-521.

Parkinson Study Group (1993). Effects of tocopherol and deprenyl on the progression of disability in early Parkinson's disease. New England Journal of Medicine 328, 176-183.

Perl, D. P. \& Good, P. F. (1987). Uptake of aluminium into central nervous system along nasal-olfactory pathways. Lancet i, 1028.

Perry, T. L., Yong, V. W., Bergeron, C., Hansen, S. \& Jones, K. (1987). Amino acids, glutathione, and glutathione transferase activity in the brains of patients with Alzheimer's disease. Annals of Neurology 21, 331-336.

Petit, T. L., Alfano, D. P. \& LeBoutillier, J. C. (1983). Early lead exposure and the hippocampus: a review and recent advances. Neurotoxicology 4, 79-94.

Powell, J. J. \& Thompson, R. P. H. (1993). The chemistry of aluminium in the gastrointestinal lumen and its uptake and absorption. Proceedings of the Nutrition Society 52, 241-253.

Prusiner, S. B. (1991). Molecular biology of prion diseases. Science 252, 1515-1522.

Quartley, B., Esselmont, G., Taylor, A. \& Dobrota, M. (1993). Effect of oral aluminium citrate on short-term tissue distribution of aluminium. Food and Chemical Toxicology 31, 543-548.

Rifat, S. L. (1994). Aluminium hypothesis lives. Lancet 343, 3-4. 
Rifat, S. L., Eastwood, M. R., McLachlan, D. R. C. \& Corey, P. N. (1990). Effect of exposure of miners to aluminium powder. Lancet 336, 1162-1165.

Rogers, J., Kirby, L. C., Hempelman, S. R., Berry, D. L., McGeer, P. L., Kasniak, A. W., Zalinski, J., Cofield, M., Mansukhani, L., Willson, P. \& Kogan, F. (1993). Clinical trial of indomethacin in Alzheimer's disease. Neurology 43, 1609-1611.

Rosenberg, I. H. \& Miller, J. W. (1992). Nutritional factors in physical and cognitive function of elderly people. American Journal of Clinical Nutrition 55, 1237S-1243S.

Roskams, A. J. \& Connor, J. R. (1990). Aluminum access to the brain: a role for transferrin and its receptor. Proceedings of National Academy of Sciences, USA 87, 9024-9027.

Sachdev, P. (1993). The neuropsychiatry of brain iron. Journal of Neuropsychiatry and Clinical Neurosciences 5, 18-29.

Sakamoto, W., Fujie, K., Handa, H., Ogihara, T. \& Mino, M. (1990). In vivo inhibition of superoxide production and protein kinase $\mathrm{C}$ activity in macrophages from vitamin E-treated rats. International Journal for Vitamin and Nutrition Research 60, 338-342.

Sato, P. H. \& Hall, E. D. (1992). Tirilazad mesylate protects vitamins C and E in brain ischemia-reperfusion injury. Journal of Neurochemistry 58, 2263-2268.

Saunders, A. M., Strittmatter, W. J., Schmechel, D., St George-Hyslop, P. H., Pericak-Vance, M. A., Joo, S. H., Rosi, B. L., Cusella, J. F., McLachlan, D. R. C., Alberts, M. J., Hulette, C., Crain, B., Goldgaber, D. \& Roses, A. D. (1993). Association of apolipoprotein $E$ allele $\epsilon 4$ with late-onset familial and sporadic Alzheimer's disease. Neurology 43, 1467-1472.

Sawada, M., Sester, U. \& Carlson, J. C. (1992). Superoxide radical formation and associated biochemical alterations in the plasma membrane of brain, heart, and liver during the lifetime of the rat. Journal of Cellular Biochemistry 48, 296-304.

SENECA (1991). Intake of vitamins and minerals. European Journal of Clinical Nutrition 45, $121-138$.

Singhrao, S., Cole, G., Henderson, W. J. \& Newman, G. R. (1990). LR white embedding allows a multi-method approach to the analysis of brain tissue from patients with Alzheimer's disease. Histochemical Journal 22, 257-268.

Smith, C. D., Carney, J. M., Starke-Reed, P. E., Oliver, C. N., Stadtman, E. R., Floyd, R. A. \& Markesbery, W. R. (1991). Excess brain protein oxidation and enzyme dysfunction in normal aging and in Alzheimer disease. Proceedings of National Academy of Sciences, USA 88, 10540-10543.

Sokol, R. J. (1989). Vitamin E and neurologic function in man. Free Radical Biology \& Medicine 6, $189-207$.

Sommer, B. R. \& Wolkowitz, O. M. (1988). RBC folic acid levels and cognitive performance in elderly patients: a preliminary report. Biological Psychiatry 24, 352-354.

Sonderer, B., Wild, P., Wyler, R., Fontana, A., Peterhans, E. \& Schwyzer, M. (1987). Murine glia cells in culture can be stimulated to generate reactive oxygen. Journal of Leukocyte Biology 42, 463-473.

Strittmatter, W. J., Weisgraber, K. H., Huang, D. Y., Dong, L.-M., Salveson, G. S., Pericak-Vance, M., Schmechel, D., Saunders, A. M., Goldgaber, D. \& Roses, A. D. (1993). Binding of human apolipoprotein $E$ to synthetic amyloid $\beta$ peptide: isoform-specific effects and implications for late-onset Alzheimer's disease. Proceedings of National Academy of Sciences, USA 90, 8098-8102.

Takashima, S., Kuruta, H., Mito, T., Houdou, S., Konomi, H., Yao, R. \& Onodera, K. (1990). Immunochemistry of superoxide dismutase-1 in developing human brain. Brain Development 12, $211-213$.

Taylor, G. A., Ferrier, I. N., McLoughlin, I. J., Fairbairn, A. F., McKeith, I. G., Lett, D. \& Edwardson, J. A. (1992). Gastrointestinal absorption of aluminium in Alzheimer's disease: response to aluminium citrate. Age and Ageing 21, 81-90.

Théry, C., Chamak, B. \& Mallat, M. (1991). Cytotoxic effect of brain macrophages on developing neurons. European Journal of Neuroscience 3, 1155-1164.

Thompson, C. M., Markesbery, W. R., Ehmann, W. D., Mao, Y.-X. \& Vance, D. E. (1988). Regional brain trace-element studies in Alzheimer's disease. Neurotoxicology 9, 1-8.

Van Rhijn, A. G., Prior, C. A. \& Corrigan, F. M. (1990). Dietary supplementation with zinc sulphate, sodium selenite and fatty acids in early dementia of Alzheimer's type. Journal of Nutritional Medicine 1, 259-266.

Ward, N. I. \& Mason, J. A. (1987). Neutron activation analysis techniques for identifying elemental status in Alzheimer's disease. Journal of Radioanalytical and Nuclear Chemistry 113, 515-526.

Wenk, G. L. \& Stemmer, K. L. (1983). Suboptimal dietary zinc intake increases aluminum accumulation into the rat brain. Brain Research 288, 393-395.

Wisniewski, H. M., Sturman, J. A. \& Shek, J. W. (1982). Chronic model of neurofibrillary changes induced in mature rabbits by metallic aluminum. Neurobiology of Aging 3, 11-22. 
Yasui, M., Yase, Y., Ota, K. \& Garruto, R. M. (1991). Evaluation of magnesium, calcium, and aluminum metabolism in rats and monkeys maintained on calcium-deficient diets. Neurotoxicology 12, 603-614.

Yue, T.-L., Barone, F. C., Gu, J.-L. \& Feuerstein, G. Z. (1993). Brain $\alpha$-tocopherol levels are not altered following ischemia/reperfusion-induced cerebral injury in rats and gerbils. Brain Research 610, 53-56.

Zaman, Z., Roche, S., Fielden, P., Frost, P. G., Niriella, D. C. \& Cayley, A. C. D. (1992). Plasma concentrations of vitamins $\mathrm{A}$ and $\mathrm{E}$ and carotenoids in Alzheimer's disease. Age and Ageing 21, 91-94.

Zetzsche, T. \& Chan-Palay, V. (1992). MAO A and B immunoreactivity in the hippocampus, temporal cortex and cerebellum of normal controls and of patients with senile dementia of the Alzheimer type. Dementia 3, 270-281. 